\title{
A 3' exonuclease activity degrades the pseudogene 5S RNA transcript and processes the major oocyte 5S RNA transcript in Xenopus oocytes
}

\author{
Yan Yan Xing and Abraham Worcel \\ Department of Biology, University of Rochester, Rochester, New York 14627 USA
}

Transcription of the major oocyte 5S RNA gene (o) and pseudogene $(\psi)$ of Xenopus laevis yields different RNAs with three different homologous systems: oocyte microinjection, whole oocyte extract, and fractionated TFIIIA + TFIIIB + TFIIIC components. Those peculiar results are caused by a 3' RNA exonuclease activity, which is inhibited in the oocyte extract, that rapidly degrades the pseudogene 5S RNA but does not degrade as readily the chimeric RNA transcripts generated by HindIII-truncated 5S RNA pseudogenes. The same, or a similar, RNase activity processes the 130- and the 142-base-long transcripts of the major oocyte 5S RNA gene into mature 120-base-long 5S RNA. We performed site-specific mutagenesis on the somatic 5S RNA gene and changed specific nucleotides on the somatic 5S RNA. These studies indicated that the structure that confers stability to the 5S RNA in vivo and in vitro is the 9-bp helix formed in 5S RNA, but not in 45 S RNA, by the complementary $5^{\prime}$ and $3^{\prime}$ ends of the molecule.

[Key Words: 5S RNA secondary structure; $3^{\prime}$ RNase; 5S RNA pseudogene expression; RNA processing]

Received March 16, 1989; revised version accepted May 3, 1989.

The highly reiterated genes that code for the $5 \mathrm{~S}$ ribosomal RNA of Xenopus laevis are organized into three gene families, each of which produces a distinct type of 5S RNA: major-oocyte, trace-oocyte, and somatic 5S RNA (Brown et al. 1977; Fedoroff and Brown 1978; Miller et al. 1978; Peterson et al. 1980; for review, see Korn 1982). The three gene types are expressed in Xenopus oocytes, but only the somatic genes are active in Xenopus somatic cells (Wegnez et al. 1972; Ford and Southern 1973). The Xenopus 5S RNA genes have been analyzed intensively in the hope of gaining an insight to the mechanism responsible for their differential expression (for review, see Wolffe and Brown 1988).

The major-oocyte family of 5S RNA genes is unusual in three respects: it is much more reiterated than the other two gene families $(20,000$ copies per haploid Xenopus genome, as opposed to 1300 copies of the traceoocyte 5S RNA genes and only 400 copies of the somatic 5S RNA genes); it produces 130- and 142-base-long transcripts in addition to the standard 120-base-long 5S RNA transcript (Bogenhagen and Brown 1981); and it contains a pseudogene (Jacq et al. 1977b). Although 5S RNA pseudogene clones are transcribed efficiently in vivo (in oocyte microinjection experiments, Miller and Melton 1981 ) and in vitro (in oocyte extracts, Bogenhagen and Brown 1981; Peck et al. 1987; Xing and Worcel 1989|, pseudogene 5S RNA has not been detected in Xenopus somatic cells or in oocytes (Wegnez et al. 1972; Ford and Southern 1973; Jacq et al. 1977b).

The repeat unit of the major-oocyte 5S DNA was cloned originally after HindIII cleavage of the Xenopus satellite 5S DNA (Fedoroff et al. 1978). The HindIII construct interrupts the 5S RNA pseudogene and generates transcripts in vivo (Miller and Melton 1981) and in vitro (Bogenhagen and Brown 1981; Peck et al. 1987) that terminate within the particular vector DNA used for cloning. Such pseudogene transcripts are chimeric molecules that carry a 114-base-long Xenopus 5S RNA pseudogene sequence at their $5^{\prime}$ and a prokaryotic RNA sequence of variable length at its $3^{\prime}$ end (see Miller and Melton 1981). Recently we obtained the nontruncated 5S RNA pseudogene and observed that it produces a standard 120-base-long RNA in the oocyte extract (Xing and Worcel 1989|. However, as we show here, this RNA does not accumulate in vivo when the 5S RNA pseudogene is microinjected into Xenopus oocytes.

The studies presented below indicate that the peculiar and apparently conflicting results obtained with the $5 \mathrm{~S}$ RNA pseudogene are caused by a 3' RNase activity that rapidly degrades the pseudogene's 5 S RNA transcript but does not degrade as readily chimeric RNA transcripts generated by the HindIII-truncated 5S RNA pseudogene. We show also that the same, or a similar, RNase activity processes the 130- and 142-base-long transcripts of the 
major oocyte 5S RNA gene into mature 120-base-long 5S RNA, and we identify the RNA structure that blocks further degradation of the 5S RNA.

\section{Results \\ Repeating units of the major oocyte SS DNA carrying a complete 5S RNA pseudogene}

The major oocyte 5S DNA is organized in tandemly repeated units in the genomic DNA of $X$. laevis (Fig. la). Each unit is composed of two distinct halves: a conserved GC-rich half that carries the gene and the pseudogene, and a more variable AT-rich half, the spacer DNA, that carries a number of repeated AT-rich blocks. The number of AT-rich repeat blocks varies among different units, and this accounts for the variable length, between $600 \mathrm{bp}$ and $1000 \mathrm{bp}$, of the repeat unit (Fedoroff and Brown 1978). Of the many possible units of this tandemly repeated DNA, only one, the HindIII unit, has been constructed. This construct lacks the stretch of six Ts (position 117-122, see Fig. 1b) that serve to terminate transcription of the 5S RNA pseudogene, and transfers them to the left end of the HindIII unit where they become part of the first block of AT-rich repeats in the spacer DNA (Fedoroff and Brown 1978).

Previously we cloned the uninterrupted 5S RNA pseudogene and observed that it is active in the oocyte S-150 where it produces a 5S RNA transcript of normal length (Xing and Worcel 1989). This prompted us to examine the expression of a repeat unit that carried the uninterrupted 5S RNA pseudogene. Initial attempts to clone such a unit from the dimer HindIII repeat, used previously to clone the pseudogene, failed. There are two DraI sites within the spacer DNA of this repeat, but none of the DraI fragments isolated from a partial DraI digest could be recovered after cloning. The problem resulted from the AT-rich repeat blocks present at both ends of such DNA fragments, which destabilize DNA in the standard Escherichia coli strains used for cloning. Eventually we obtained and propagated such clones using the appropriate $E$. coli rec ${ }^{-}$strains, as described in Materials and methods. The DraI unit shown in Figure la was one of the repeats obtained that carried the uninterrupted pseudogene. The other cloned units with a complete pseudogene also behaved as described below for this DraI unit. Only the HindIII unit behaved in an anomalous manner by generating chimeric pseudogenevector RNA transcripts in vivo and in vitro.

Transcription of the uninterrupted 5S RNA pseudogene in the oocyte S-150 generates a 120-base-long 5S RNA

We used partially denaturing $4 \mathrm{~m}$ urea gels to separate RNA molecules of the same size but of different sequence (Wakefield and Gurdon 1983), and fully denaturing $8 \mathrm{M}$ urea gels to resolve RNA molecules by size. The DNA clones described in Figure 1 generated in the oocyte S-150 the RNA molecules displayed in Figure 2.

The DraI unit of the major oocyte 5S DNA generated the standard major oocyte and pseudogene transcripts (see D, Fig. 2a, lane 3). Transcription termination on the major oocyte 5S RNA gene occurred at positions 120 , 130 , and 142 , and transcription termination of the uninterrupted 5S RNA pseudogene occurred at position 120 (Bogenhagen and Brown 1981; see Fig. 1b). The 120-base pseudogene 5S RNA $(\psi)$ comigrated with the 120-base oocyte 5S RNA (o) in $8 \mathrm{~m}$ urea gels (Fig. 2b, lane 3), but these two 120-base-long RNA molecules were resolved in $4 \mathrm{M}$ urea gels (Fig. 2a, lane 3). For reasons that are still unclear (see Millstein et al. 1987; Peck et al. 1987; Wolffe 1988; Xing and Worcel 1989|, the major oocyte 5S RNA gene was transcribed poorly in the oocyte S-150, and as a result, the pseudogene 5S RNA was by far the most abundant transcript when the major oocyte $5 \mathrm{~S}$ DNA unit was transcribed in these extracts. The origin of these transcripts was confirmed by the analysis of transcripts produced by the isolated major-oocyte $5 \mathrm{~S}$ RNA gene (o, Fig. 2, lane 4), and the isolated uninterrupted 5S RNA pseudogene ( $\psi$, Fig. 2, lane 7$)$.

The transcripts generated by the HindIII unit of the major oocyte 5S DNA varied with the DNA used for cloning (Miller and Melton 1981). Here we present results obtained with two clones, one in pUC18 (Fig. 2, $\mathrm{H}^{\prime}$, lane 1) and the other pUCl3 (Fig. 2, $\mathrm{H}^{\prime \prime}$, lane 2). The amount and size of the three major oocyte 5S RNA transcripts were the same as in the case of the DraI unit, but the size of the pseudogene 5S RNA transcript was longer: 130 bases in lane $1\left(\psi^{\prime}\right)$ and about 170 bases in lane $2\left(\psi^{\prime \prime}\right)$. Transcription of the HindIII-truncated $5 \mathrm{~S}$ RNA pseudogene cloned in either pUC18 $\left(\psi^{\prime}\right.$, lane 5$)$ or pUC13 ( $\psi$, lane 6) confirmed that the abundant 130base-long RNA in lane 1 and the abundant 170-base-long RNA in lane 2 were pseudogene transcripts. Figure $1 \mathrm{~b}$ shows the DNA sequence of the distal region of these two chimeric pseudogenes: As expected, a stretch of four Ts was found within the vector DNA sequence 130 bases $\left(\psi^{\prime}\right)$ and 172 bases $\left(\psi^{\prime \prime}\right)$ downstream from the start site of the 5S RNA pseudogene transcription (see also Bogenhagen and Brown 1981; Miller and Melton 1981).

The major oocyte 5S RNA gene and the 5S RNA pseudogene generate different RNAs in other homologous transcription systems

A different pattern of transcription was obtained when the major oocyte 5S RNA gene (o), and the three 5S RNA pseudogenes $\left(\psi, \psi^{\prime}\right.$, and $\psi^{\prime \prime}$, Fig. 2) were microinjected into Xenopus oocytes. A Xenopus tRNA gene clone was coinjected with the 5S RNA gene clones to confirm the significance of the observed differences in the amounts of 5S RNA made in vivo.

Figure 3a displays the RNA molecules, resolved in a 4 $\mathrm{M}$ urea gel, that were produced during 3-hr (lanes 1-4) and 18-hr (lanes 5-8) incubations of oocytes microinjected with $\left[\alpha-{ }^{32} \mathrm{P}\right] \mathrm{GTP}$ and the indicated DNA clones. In contrast with the results obtained with the S-150, the major oocyte 5S RNA gene was transcribed efficiently in vivo. Furthermore, of the three major oocyte 5S RNAs made, only the correct, 120-base-long 5S RNA accumulated after an 18-hr incubation in vivo (Fig. 3a, cf. lanes 1 


\section{Xing and Worcel}

a

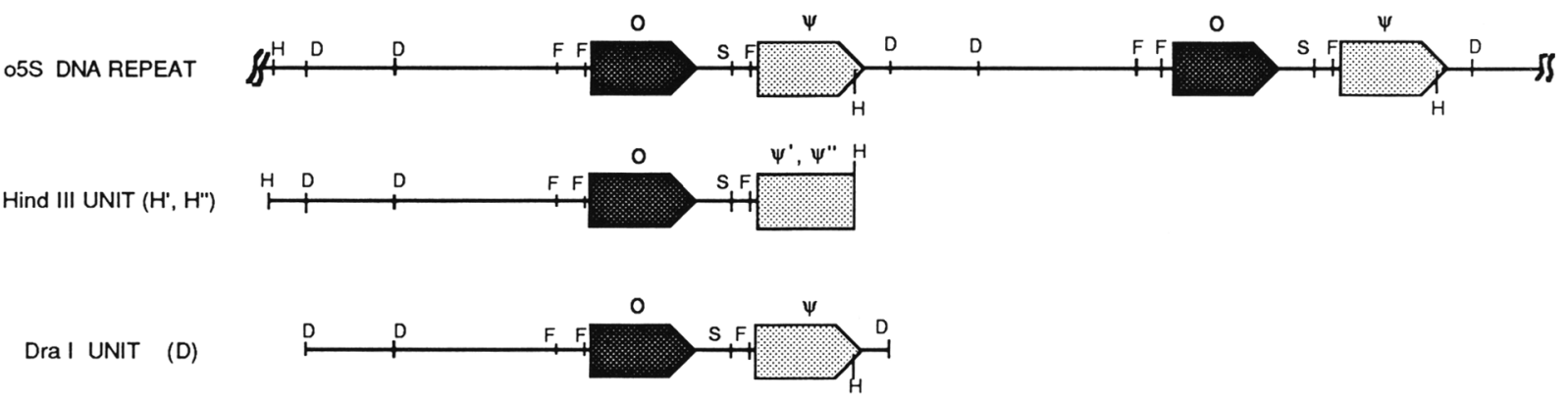

o5S GENE(O)

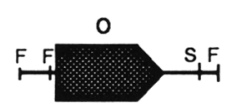

5S PSEUDOGENE $(\Psi)$

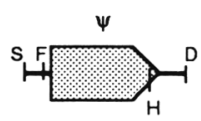

$\stackrel{\longmapsto}{100 \mathrm{bp}}$

5 S PSEUDOGENE( $\left.\psi^{\prime}, \psi^{\prime \prime}\right)$

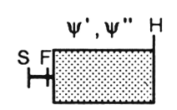

b

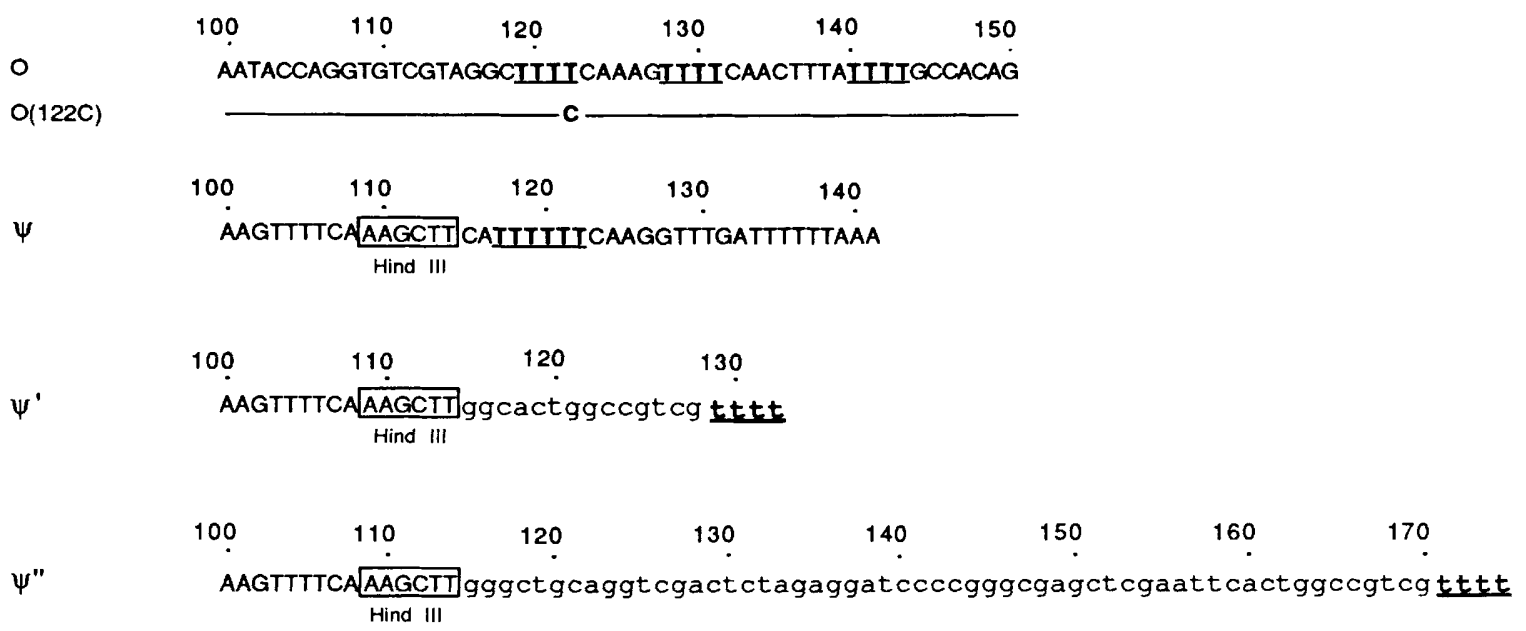

Figure 1. (a) Clones of major oocyte 5S DNA unit, major oocyte 5S RNA gene, and 5S RNA pseudogene that were used in these studies. (H) HindIII; (D) DraI; (F) Fnu4HI; (S) SfaNI. (b) Nucleotide sequences of the transcription termination region of the 5S RNA gene clones. (o) Major oocyte 5S RNA gene; [o (122 C)] $122 \mathrm{~T} \rightarrow \mathrm{C}$ terminator mutant of major oocyte 5S RNA gene; ( $\psi$ ) 5S RNA pseudogene; $\left(\psi^{\prime}\right\rangle$ HindIII-truncated pseudogene inserted in pUC18 $\left(\psi^{\prime \prime}\right\rangle$ HindIII-truncated pseudogene inserted in pUC13. Xenopus sequences are uppercase; prokaryotic vector sequences are lowercase. The numbering starts at the $5^{\prime}$ end of the transcripts $(+1)$. The stretch of Ts used as transcription termination signals by RNA polymerase III are underlined.

and 5). In agreement with previous results (Miller and Melton 1981), the chimeric pseudogenes also were transcribed efficiently in vivo /see Fig. $3 a, \psi^{\prime}$ in lanes 2 and 6 , and $\psi^{\prime \prime}$ in lanes 3 and 7). In contrast, the authentic 120base-long pseudogene 5S RNA was present at substantially reduced levels after microinjection of the uninter- rupted pseudogene /see Fig. 3a, $\psi$ in lanes 4 and 8 ; note also that the $\psi$ RNA band migrates as a doublet in this gel).

A somewhat similar RNA pattern was obtained when these clones were transcribed in vitro for $3 \mathrm{hr}$ (Fig. 3b, lanes 1-4) or $18 \mathrm{hr}$ (Fig. 3b, lanes 5-8) with the fraction- 


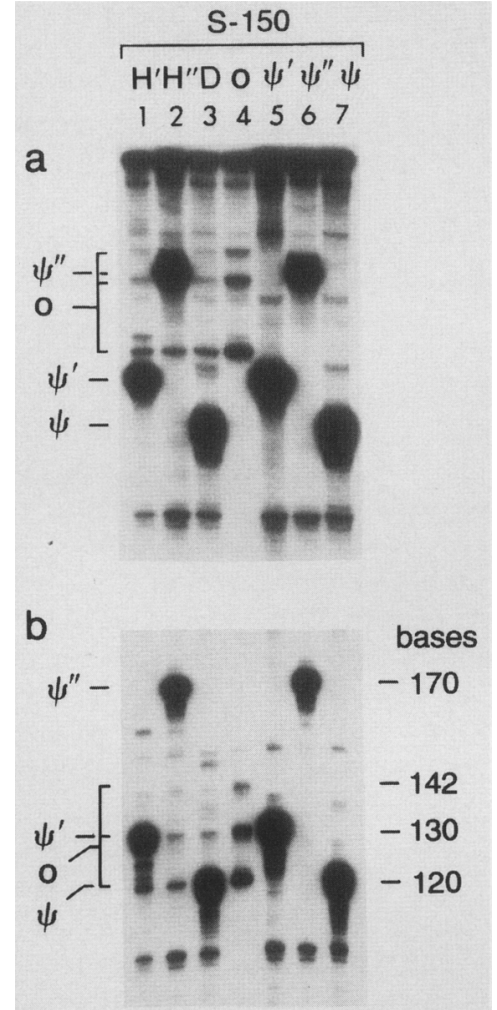

Figure 2. Transcription in the S-150 of the clones of major oocyte 5S DNA unit, major oocyte 5S RNA gene, and 5S RNA pseudogene (see Fig. 1). The labeled RNAs were resolved in $4 \mathrm{M}$ urea-polyacrylamide gels $(a)$, and $8 \mathrm{M}$ urea-polyacrylamide gels $\langle b\rangle$.

ated TFIIIA + TFIIIB + TFIIIC components of Xenopus oocytes (see Materials and methods). The major oocyte 5S RNA gene formed predominantly the 120-base-long transcript (Fig. 3b, lane 1 and 5), whereas the chimeric pseudogenes generated the 130-base-long RNAs $\left(\psi^{\prime}\right.$, lanes 2 and 6$)$ and the 170-base-long RNAs $\left(\psi^{\prime \prime}\right.$, lanes 3 and 7). In contrast, very little 120 -base-long pseudogene 5S RNA $(\psi)$ was seen when the uninterrupted 5S RNA pseudogene was incubated under these same conditions; as shown in lanes 4 and 8 in Figure $3 \mathrm{~b}$, most of the labeled RNA molecules detected were smaller than the full-length 5S RNA pseudogene transcript.

\section{A 3' RNase activity, which is inhibited in the S-150, is} present in the phosphocellulose fraction $B$

The simplest interpretation for the results presented above is that authentic pseudogene 5S RNA is degraded in vivo and in vitro by an RNase activity that is inhibited in the whole-cell extract, and that this activity does not degrade the abnormal pseudogene transcripts $\psi^{\prime}$ and $\psi^{\prime \prime}$ so readily (although some smaller RNA molecules also were detected with these truncated pseudogene clones, see Figs. 2 and 3). The same or a similar activity also may be responsible for processing the long major oocyte 5S RNA transcripts, and this could account for the higher amounts of 120-base-long 5S RNA molecules observed after long incubations of the major oocyte $5 \mathrm{~S}$ RNA gene, in vivo (Fig. 3a, lane 5) and in vitro (Fig. 3b, lane 5).

To test this hypothesis, we synthesized somatic, major oocyte, and pseudogene 5S RNA molecules by transcribing the appropriate DNA clones in the oocyte S-150. These RNA molecules were purified and then incubated for $1 \mathrm{hr}$ with either phosphocellulose fraction $\mathrm{B}$, fraction $C$, or a mixture of fractions $B$ and C (TFIIIA is more than $95 \%$ pure and has no detectable RNase activity, data not shown). As shown in Figure 4, the phosphocellulose fraction B contained a nuclease activity that degraded the 120-base-long pseudogene 5S RNA and the 142- and 130-base-long major oocyte 5S RNAs, but this activity did not degrade the 120-base-long major oocyte 5S RNA or the 120-base-long somatic 5S RNA.

The ladder of RNA fragments produced when the pseudogene 5S RNA (Fig. 4, lane 10) or the long major oocyte 5S RNAs (Fig. 4, lane 6) were incubated with fraction $B$ indicates that the activity was an exonuclease that cleaved the RNA molecules from one end. Because the 120-base-long oocyte 5S RNA is stable and the 130and 142-base-long oocyte 5S RNAs are not stable, and because these RNA molecules differ only at their $3^{\prime}$ end (see Fig. 1b for the nucleotide sequence at the $3^{\prime}$ end of the major oocyte 5S RNA genel, we may infer that the RNase activity was a $3^{\prime}$ exonuclease.

The last two lanes in Figure 4 show that the 170-baselong chimeric pseudogene transcript $\left(\psi^{\prime \prime}\right)$ was resistant to the RNase activity present in fraction B (although low levels of pseudogene-type limit digest could be detected under these conditions, see arrow in Fig. 4). We have not pursued further the studies with the chimeric transcripts because such molecules do not occur naturally in Xenopus.

A $3^{\prime}$ exonuclease activity degrades the pseudogene $5 \mathrm{~S}$ $R N A$ and processes the long major oocyte $5 S$ RNAs to mature 120-base-long 5S RNA

The activity that degraded the pseudogene 5S RNA and the long oocyte 5S RNAs was not inactivated by preincubation with micrococcal nuclease (data not shown), which implies that it does not require snRNPs (see, Krainer and Maniatis 1985), but it was inactivated by temperature $\left(56^{\circ} \mathrm{C}\right)$ and EDTA (10 $\left.\mathrm{mm}\right)$. Parallel inactivation curves were obtained with the long major oocyte RNAs or the pseudogene 5S RNA as substrates (Fig. 5), which suggests that the same enzyme was responsible for both activities. These two activities comigrated also in a salt gradient elution of a DEAE-52 cellulose column, in this column, the exonuclease was eluted ahead of transcription factor B (data not shown).

The increased levels of 120-base-long RNA after oocyte 5S RNA transcripts were incubated with fraction B (Figs. 4 and 5) suggest that the long RNA moieties were being processed to the 120 -base mature $5 \mathrm{~S}$ RNA. To prove this point, we examined the transcription and processing of a mutated major oocyte 5S RNA gene that carried a $\mathrm{T} \rightarrow \mathrm{C}$ transition at position 122 (see Fig. lb). 


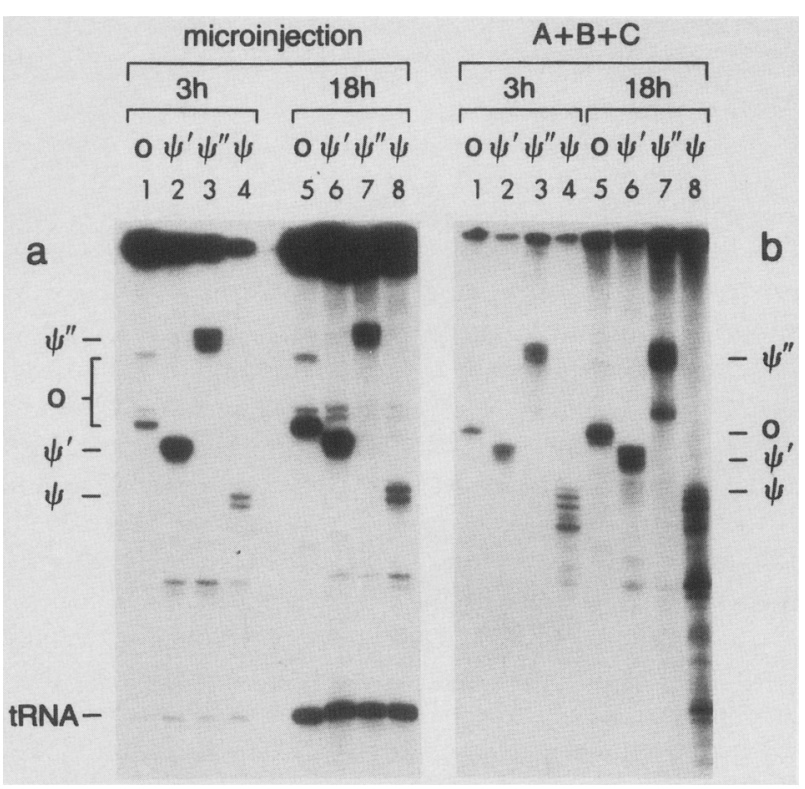

Figure 3. Transcription of the major oocyte 5S RNA gene and 5S RNA pseudogenes in germinal vesicles in vivo $(a)$ and reconstituted system of TFIIIA + TFIIIB + TFIIIC-polIII $(b)$ /see Materials and methods). The labeled RNAs in this and in the following figures were resolved in $4 \mathrm{M}$ urea-polyacrylamide gels. (tRNA) Transcript of the $X$. laevis tRNA ${ }^{\text {met }}$ gene clone that was coinjected with the 5S RNA gene clones (see Materials and methods|.

Such a mutation inactivated the first RNA terminator of this gene (Bogenhagen and Brown 1981). The effects of this single-base substitution were examined both in the wild-type major oocyte 5S RNA gene background and in a mutated major oocyte 5S RNA gene background, o (53C, 55A, and 56G), that enhanced the level of oocyte 5S RNA transcription (Xing and Worcel 1989).

As shown in Figure 6a, inactivation of the first RNA terminator had no major effect on the amounts or types of oocyte 5S RNA produced after microinjection into Xenopus oocytes. After an 18 -hr incubation of the microinjected oocytes, a 120-base-long transcript still accumulated when the mutated gene was used, although the relative amount of the 120-base-long RNA was somewhat lower than it was when a gene with the wildtype terminator was injected (cf. lanes 1 and 2, Fig. 6a).

The accumulation of correct, 120-base-long 5S RNA when the oocyte (122 C) mutant gene was microinjected into Xenopus oocytes was probably the result of RNA processing because no 120-base-long RNA was detected when this mutant gene was transcribed in the S-150 (Fig. $6 \mathrm{~b}$, lanes 3 and 5). Furthermore, when the 130- and the 142-base-long RNAs generated by this mutant in the S-150 were incubated with the phosphocellulose fraction $B$, they were processed readily into mature 120 base-long 5S RNA (Fig. 6b, lanes 4 and 6).

A similar 3' exonuclease activity is detected in vivo by RNA microinjection into oocyte nucleus or cytoplasm

To prove that the RNase activity detected in vitro was biologically relevant, we examined the fate of the various 5S RNA molecules in vivo, after their microinjection into Xenopus oocytes. In this series of experiments, purified RNA molecules (which were synthesized in the S-150 in the presence of high specific activity $\left[\alpha^{-32}\right]$ GTP, see Materials and methods) were coinjected in pairs to control for possible artifactual variations in RNA stability among different injected oocytes.

As shown in Figure 7, RNase activity was detected in vivo when the RNA was injected into either the nucleus or the cytoplasm, and this activity had the same sequence specificity as the activity that was present in the phosphocellulose fraction B. The amount of 120-baselong pseudogene 5S RNA $(\psi)$ was reduced, whereas the amount of 120-base-long oocyte 5S RNA was enhanced in the injected oocytes (Fig. 7, lanes 1-3).

The amount of chimeric 130-base-long pseudogene RNA $\left(\psi^{\prime}\right)$ also was reduced after microinjection, although the RNA breakdown was not as pronounced as the breakdown of the authentic 120-base-long pseudogene 5S RNA /cf. lanes 5 and 6 with lanes 2 and 3 in Fig. 7). Under the same conditions, the RNAs produced by the oocyte $(122 \mathrm{C})$ terminator mutant showed increased levels of 120-base-long RNA and decreased levels of 130and 142-base-long RNAs (see Fig. 7, lanes 4-9), which indicates that the long oocyte $5 S$ RNAs were processed in vivo to the mature 120-base-long oocyte 5S RNA.

In the last set of experiments shown in Figure 7, we

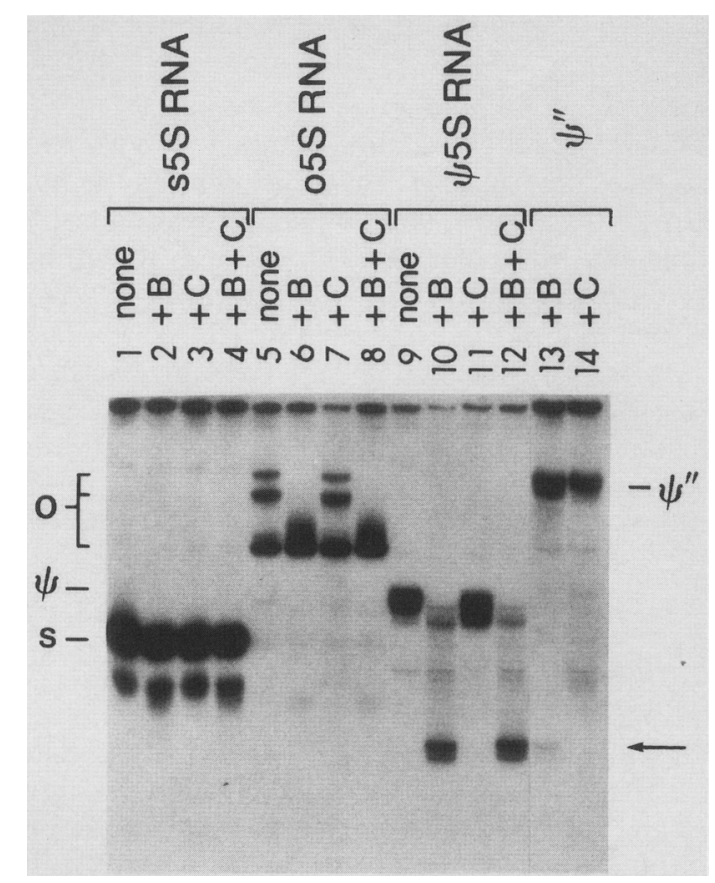

Figure 4. A $3^{\prime}$ RNase activity is present in the phosphocellulose fraction $\mathrm{B}$. The labeled $5 \mathrm{~S}$ RNAs were incubated with the phosphocellulose fractions as described in Materials and methods. (Lane none) Without addition of phosphocellulose fractions $B$ or $C$; (lane $+B$ ) phosphocellulose fraction B added; (lane $+C$ ) phosphocellulose $C$ added; (lane $+B+C$ ) both phosphocellulose fraction $B$ and $C$ added; (s) somatic $5 S$ RNA. 


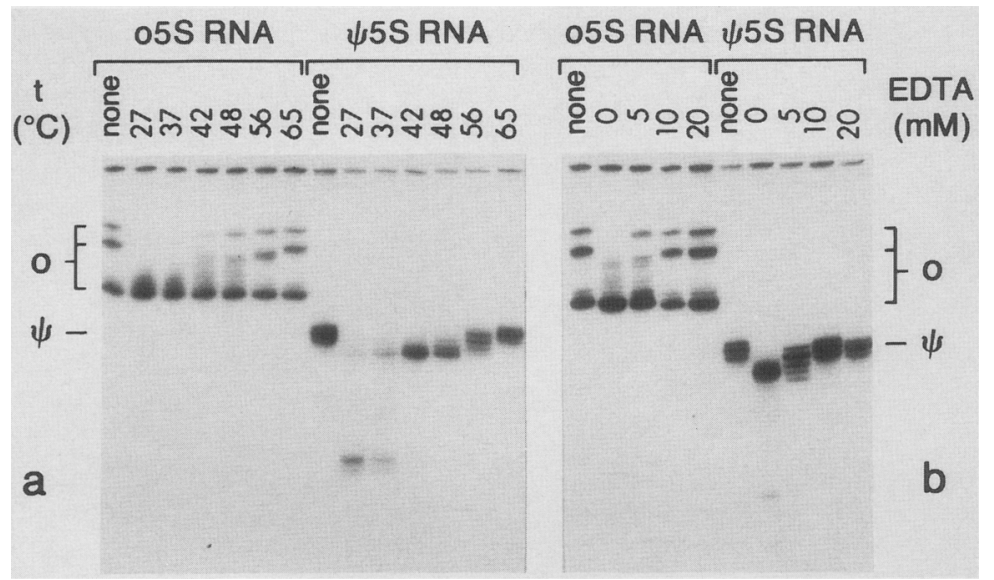

Figure 5. Inactivation of the $3^{\prime}$ exonuclease by temperature $(a)$ and by EDTA $(b) .(a)$ The phosphocellulose fraction B was preincubated at different temperatures for $15 \mathrm{~min}$ in the processing reaction mix without 5S RNA. The mixture then was placed at $25^{\circ} \mathrm{C}$, and either oocyte $5 \mathrm{~S}$ RNA or pseudogene $5 \mathrm{~S}$ RNA was added to begin the processing reaction. $(b)$ The oocyte 5S RNA or pseudogene 5S RNA was incubated with the phosphocellulose fraction $B$ in the presence of different concentrations of EDTA. (Lane none) No addition of phosphocellulose fraction $\mathrm{B}$. microinjected a somatic 5S RNA that carried two pseudogene-type changes near the $3^{\prime}$ end of the RNA molecule (115C, 116A, also see below). Such a mutated 5S RNA was not stable in vivo and was degraded like the pseudogene 5S RNA (lanes 7-9).

The 3' exonuclease activity is blocked by the 9-bp helix generated by the complementary $5^{\prime}$ and $3^{\prime}$ ends of the 5S RNA; base changes within the helix that result in mispairing cause $5 S$ RNA degradation; complementary base changes that restore base-pairing restore 5S RNA stability

Processing of the long major oocyte 5S RNA precursors into mature 120 -base-long oocyte 5S RNA may be catalyzed by a $3^{\prime}$ exonuclease that cleaves single-stranded RNA tails but does not cleave double-stranded RNA structures. Although no eukaryotic $3^{\prime}$ exonuclease has been purified yet, a number of prokaryotic RNases are known to act in such a manner (Deutscher 1985). The 142-base-long major oocyte 5S RNA precursor is folded in Figure 8a in the characteristic and universal 5S RNA secondary structure (see, Romaniuk et al. 1988; Wolters and Erdmann 1988). In this folding pattern, the 22-baselong overhanging tail is a good substrate for a $3^{\prime}$ exonuclease, and the 9-bp helix formed by the complementary $5^{\prime}$ and $3^{\prime}$ ends of the mature 5S RNA is a good candidate for the structure that prevents further RNA breakdown. This type of RNA folding also can explain the breakdown of the pseudogene 5S RNA: most of the nucleotide differences between pseudogene 5S RNA and oocyte $5 \mathrm{~S}$ RNA occur at the $3^{\prime}$ end of the molecule (see Fig. 1b), and those base changes destroy the complementarity between the $5^{\prime}$ and $3^{\prime}$ ends of the molecule (Fig. 8 b).

To prove that the 9-bp helix is the structure responsible for conferring stability to the 5S RNA, we changed specific bases in the somatic 5S RNA. This was accomplished by site-specific mutagenesis on the 5S DNA followed by transcription of the mutated 5S DNAs in the S-150 (see Materials and methods). In a first step, we mutated two bases near the $3^{\prime}$ end of the molecule, 115 $\mathrm{A} \rightarrow \mathrm{C}$ and $116 \mathrm{G} \rightarrow \mathrm{A}$. The changed $3^{\prime}$ nucleotides were no longer complementary to the corresponding $5^{\prime} \mathrm{nu}$ cleotides (Fig. 8c). As shown in Figure 7, this mutated 5S RNA was not stable in Xenopus oocytes.

Next we changed additional bases on the $5^{\prime}$ region of the mutated $(115 \mathrm{C}, 116 \mathrm{~A})$ 5S RNA: $3 \mathrm{C} \rightarrow \mathrm{U}$ and 4 $\mathrm{U} \rightarrow \mathrm{G}$, to restore base-pairing (but not base sequence) on the 9-bp stem (Fig. 8c). Finally, to ascertain whether the complete 9-bp helix was required for 5S RNA stability, we introduced one additional nucleotide change on this mutated 5S RNA, $6 \mathrm{C} \rightarrow \mathrm{A}$; by changing $1 \mathrm{nu}$ -

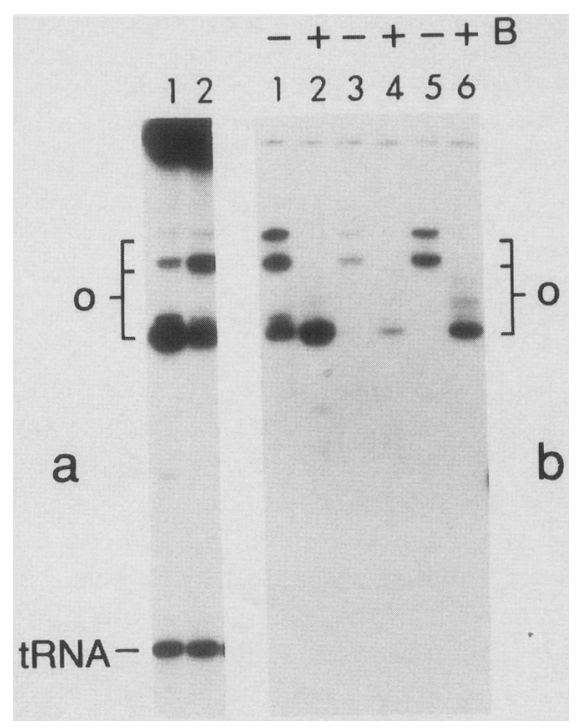

Figure 6. The $3^{\prime}$ exonuclease activity processes the long major oocyte 5S RNAs to mature 120-base-long 5S RNA. (a) Transcripts produced in vivo after oocyte microinjection of the major oocyte 5S RNA gene (lane 1) and the terminator mutant $(122 \mathrm{~T} \rightarrow \mathrm{C})$ of the major oocyte 5S RNA gene (lane 2). (b) In vitro processing of $5 S$ RNAs that were synthesized in the S- 150 using the oocyte (53C, 55A, 56G) gene (lanes 1 and 2), the terminator mutant $(122 \mathrm{~T} \rightarrow \mathrm{C})$ in the wild-type oocyte gene background (lanes 3 and 4), the terminator mutant $(122 \mathrm{~T} \rightarrow \mathrm{C})$ in the oocyte (53C, 55A, 56G) gene background (lanes 5 and 6). (B) Phosphocellulose fraction $\mathrm{B}$. 


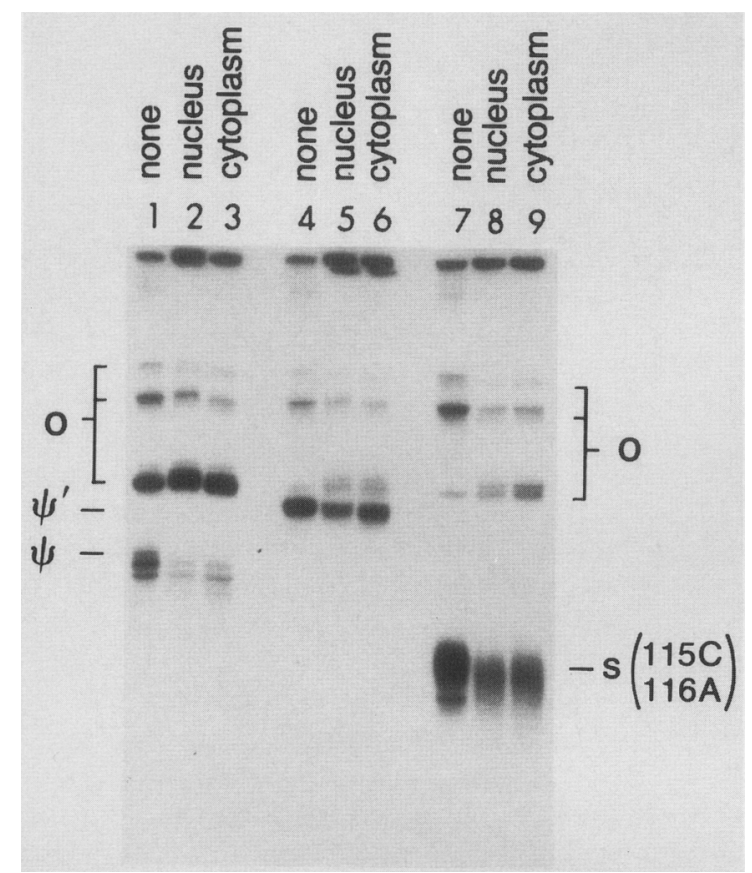

Figure 7. RNA processing in oocytes microinjected with labeled RNAs. The labeled 5S RNAs, which were made in S-150, were mixed in pairs and then injected into either the nucleus or the cytoplasm of $X$. laevis oocytes. (Lanes 1-3) Major oocyte 5S RNA (o) and pseudogene 5S RNA $(\psi)$; (lanes 4-6) 5S RNA made by the oocyte 5S DNA (122C) terminator mutant and 5S RNA made by the chimeric 5S DNA pseudogene $\psi^{\prime}$; (lanes 7-9) 5S RNA made by the oocyte 5S DNA (122C) terminator mutant and 5S RNA made by the somatic 5S DNA (115C, 116A) mutant. (Lanes none) RNA moieties before injection; (lanes nucleus) RNA after injection into the nucleus of oocytes; (lanes cytoplasm) RNA after injection into the cytoplasm of oocytes (see Materials and methods).

cleotide on the $5^{\prime}$ region of the 5S RNA molecule, this mutation broke $1 \mathrm{bp}$ in the 9 -bp stem (Fig. 8c).

The 5S DNA mutations described had no significant effect on transcription initiation or termination in the oocyte S-150, but they had marked effects on the stability of the 5S RNA transcripts. Figure 9a displays the labeled RNA molecules present in Xenopus oocytes microinjected with $\left[\alpha^{-32} \mathrm{P}\right] \mathrm{GTP}$ and the indicated wild-type or mutated 5S DNAs. Essentially no labeled 5S RNA could be recovered from oocytes injected with the somatic double mutant gene (115C, 116A; Fig. 9a, lane 2). The labeled 5S RNA again was recovered in a very good yield when the somatic quadruple mutant gene was injected (115C, 116A, 3T, 4G; lane 3), but only a reduced amount of labeled 5S RNA was recovered when the somatic quintuple mutant was injected $(115 \mathrm{C}, 116 \mathrm{~A}, 3 \mathrm{~T}$, 4G, 6A; lane 4).

The marked differences in the amount of labeled $5 \mathrm{~S}$ RNA seen in Figure 9a resulted from differences in the rate of breakdown of these four RNA transcripts. As shown in Figure 9b, when the purified RNA molecules, which were made in the S-150, were incubated with the phosphocellulose fraction $\mathrm{B}$, the wild-type somatic $5 \mathrm{~S}$ a

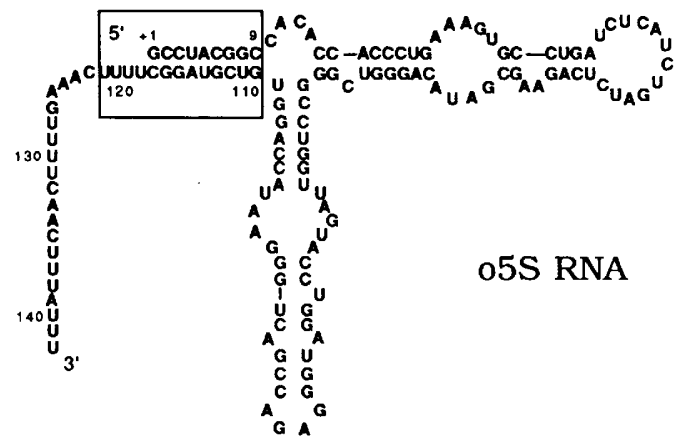

b

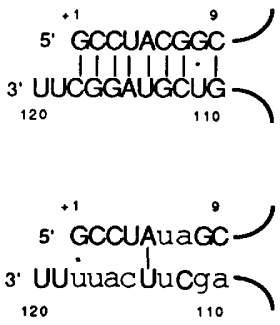

S, o5S RNA

$\psi 5$ S RNA

$\mathbf{s} 5 \mathrm{~S}(115 \mathrm{C}, 116 \mathrm{~A})$
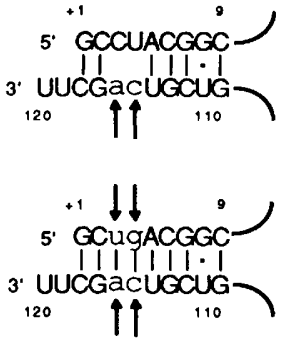

s5S (115C,116A $3 \mathrm{U}, 4 \mathrm{G})$

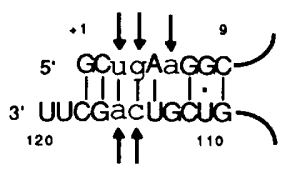

s5S $(115 \mathrm{C}, 116 \mathrm{~A}$ $3 \mathrm{U}, 4 \mathrm{G}, 6 \mathrm{~A})$

Figure 8. 5S RNA secondary structures. (a) Secondary structure of the oocyte 5S RNA of X. laevis (see, Romaniuk et al. 1988). The sequence of the boxed region is compared with the sequence of the equivalent region in other $5 S$ RNAs in $b$ and $c$. (b) Stem structure formed by the 5 ' and 3' ends of the natural $5 \mathrm{~S}$ RNAs (top) and the 5S RNA pseudogene (bottom). (c) Stem structure formed by the $5^{\prime}$ and $3^{\prime}$ ends of the mutated 5 S RNAs that were used in this work.

RNA (lanes 1 and 2) and the quadruple mutant RNA (lanes 5 and 6) were stable, whereas the double mutant RNA (lanes 3 and 4) and the quintuple mutant RNA (lanes 7 and 8) were degraded.

\section{Discussion}

Processing of RNA transcripts plays key roles in generating fully functional RNA molecules and in regulating 


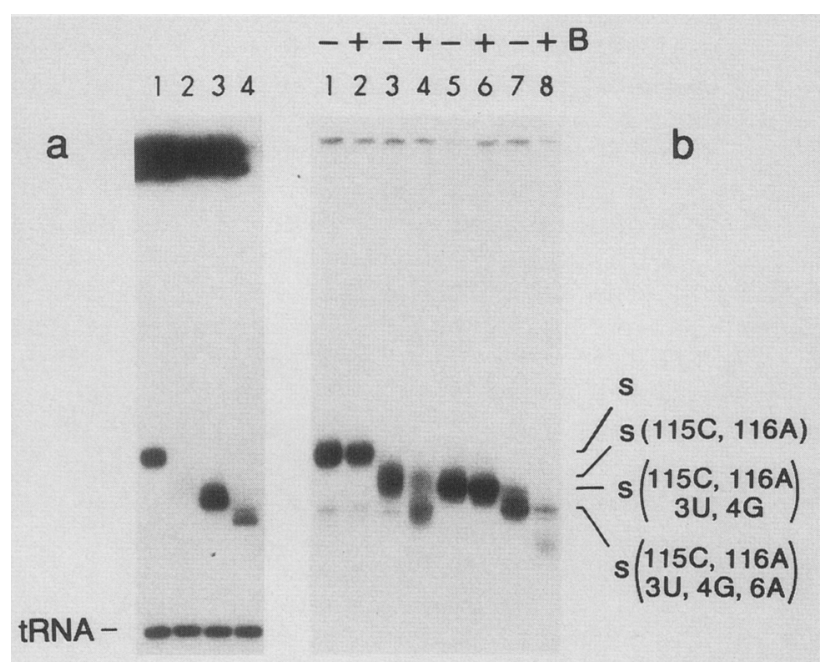

Figure 9. Stability of the wild-type and mutated somatic $5 \mathrm{~S}$ RNAs in vivo $(a)$ and in vitro $(b)$. $(a)$ The 5 S DNA plasmids were microinjected into Xenopus oocytes as follows: (lane 1) wildtype somatic 5S DNA; (lane 2) somatic (115C, 116A) double mutant; (lane 3) somatic (115C, 116A, 3T, 4G) quadruple mutant; (lane 4) somatic (115C, 116A, 3T, 5G, 6A) quintuple mutant. The RNAs were extracted after an 18-hr incubation of the injected oocytes. (tRNA) Transcript of the X. laevis tRNAmet gene clone that was coinjected with the 5S RNA gene clones. (b) The labeled 5S RNAs were synthesized in the S-150 using the same 5S DNA clones as above, and the purified RNAs were incubated without (lanes - ) or with (lanes +) phosphocellulose fraction $\mathrm{B}$ at $25^{\circ} \mathrm{C}$ for $1 \mathrm{hr}$. The nucleotide changes introduced in the somatic 5S RNA changed in the electrophoretic mobility of the partially denatured RNAs in the $4 \mathrm{M}$ urea gel, as indicated. These four RNAs migrate as 120-base-long RNAs in fully denaturing $8 \mathrm{M}$ urea gels.

the amount of such molecules within the cell (Brawerman 1987; Maniatis and Reed 1987; Sharp 1987). The transcripts of the major oocyte 5S DNA of X. laevis are no exception to this rule: The 130- and 142-base-long oocyte 5S RNAs are processed in vivo and in vitro to mature 120-base-long 5S RNA, and, under the same conditions, the 120-base-long pseudogene 5S RNA is degraded. Transcription termination on the Xenopus somatic 5S DNA and on the trace-oocyte 5S DNA does generate 120-base-long 5S RNAs (Bogenhagen and Brown 1981), but a strong terminator at +120 is not required for the formation of 120-base-long 5S RNA. In fact, inactivation of the +120 terminator on the major oocyte 5S RNA gene by the $\mathrm{T} \rightarrow \mathrm{C}$ transition at +122 does not prevent formation of a 120-base-long 5S RNA, which is produced under these circumstances by processing of the longer RNA precursors. Processing of $5 \mathrm{~S}$ RNA transcripts takes place in Drosophila (Jacq et al. 1977a) and mammalian cells also (Hamada et al. 1979).

The results presented here are biologically relevant because oocyte 5S RNA transcripts longer than $135 \mathrm{nu}$ cleotides have been detected in Xenopus ovaries, and these precursors are shortened rapidly in vivo to mature 120-base-long oocyte 5S RNA (Denis and Wegnez 1973).
The same study, as well as other in vivo studies (Wegnez et al. 1972; Ford and Southern 1973), failed to detect pseudogene type 5S RNA sequences; these negative results could be explained if the pseudogene 5S RNA is degraded. As shown in Figure 3b, when the 5S RNA pseudogene is transcribed with the fractionated TFIIIA + TFIIIB + TFIIIC components, the transcript is indeed degraded rapidly and the labeled molecules are shorter than full-length pseudogene 5S RNA.

Three reasons seem to account for previous failures to detect 5S RNA processing in Xenopus: (1) Processing is inefficient in unfractionated extracts of oocytes or germinal vesicles (Bogenhagen and Brown 1981; Peck et al. 1987; Xing and Worcel 1989); (2) experiments with fractionated TFIIIA + TFIIIB + TFIIIC components (Lassar et al. 1983; Setzer and Brown 1985; Carey et al. 1986) employed the Xenopus somatic 5S RNA gene, which produces a transcript that is not processed; and (3) experiments by microinjection employed truncated $5 \mathrm{~S}$ RNA pseudogenes (Miller and Melton 1981). Inhibition of processing of major oocyte and pseudogene 5S RNAs may be caused by a RNase inhibitor released during the preparation of the extract, or by proteins that bind to, and protect, the 5S RNA molecules; as shown here, further fractionation of the S-150 restores the activity that is detected in living oocytes. The failure to process chimeric pseudogene transcripts (Miller and Melton 1981; see Figs. 3 and 4) is probably the result of secondary structures in these molecules that block the action of the 3' RNA exonuclease; as noted previously (Cotten et al. 1988), proper transcripts must be used to examine RNA processing events. Bogenhagen and Brown (1981) reported initially that a nontruncated 5S RNA pseudogene generates a 5S RNA transcript of the correct length in germinal vesicle extracts, but, apparently, further studies with the uninterrupted pseudogene were not pursued.

Double-stranded RNA structures act as signals that can either direct or prevent RNA cleavage (for review, see Brawerman 1987). The 9-bp helix formed by the complementary $5^{\prime}$ and $3^{\prime}$ ends of the 5S RNA molecule is the signal that prevents further RNA breakdown by the 3' RNase: Naturally occurring $5 \mathrm{~S}$ RNAs are protected because they form this helix, and pseudogene $5 \mathrm{~S}$ RNA is degraded because it cannot form such a helix. This interpretation is supported by the data obtained here with the site-specific mutants: Small perturbations in the secondary structure of the 9-bp stem in somatic 5S RNA cause degradation of the mutated RNAs in vivo and in vitro. We note that the 9-bp double-stranded helix is present in both bacterial and eukaryotic 5S RNAs, although nucleotides within the helix have diverged (see, Wolters and Erdmann 1988). Phylogenetic covariation within the 9-bp stem is consistent with the notion that this double-stranded RNA structure plays a universal and essential role as a signal for processing termination. Also, it is possible that the 9-bp helix has been conbecause of its structural role in the ribosome.

The RNase activity present in the phosphocellulose fraction B from Xenopus oocytes clearly is different from 


\section{Xing and Worcel}

the RNA endonuclease activities involved in RNA splicing (Maniatis and Reed 1987; Sharp 1987). The activity described here may be the same as the 3' RNA exonuclease activity detected by Georgiev et al. (1984) in Xenopus oocytes. In addition to its role in RNA processing, and in conjunction with an RNA helicase that destroys RNA secondary structures (Bass and Weintraub 1988), such an enzyme also may play a role in the breakdown of RNA molecules within the cell.

\section{Materials and methods}

\section{Plasmid constructions}

Plasmid pXloF31 (Gargiulo et al. 1984), which carries a 660-bp HindIII repeat unit of the major-oocyte 5S DNA of $X$. laevis inserted in pUC, was digested with HindIII, and the 5S DNA insert was purified by gel elution. The 660 -bp fragment was self-ligated in head-to-tail fashion with T4 ligase to form a dimer of the HindIII repeat unit. The uninterrupted pseudogene ( $\psi$ ) was subcloned from this HindIII repeat dimer as described (Xing and Worcel 1989). The nucleotide sequence of this clone is identical to the nucleotide sequence of the uninterrupted pseudogene clone pXlo31 $\psi 1$ (Bogenhagen and Brown 1981), at least within the region +100 to +133 that contains the transcription termination signal for the 5S RNA pseudogene. To generate the truncated pseudogene clones $\psi^{\prime}$ and $\psi^{\prime \prime}$, the pseudogene clone was cleaved with HindIII, and the 187-bp HindIII fragment was inserted into pUCl8 and $\mathrm{pUC13}$, respectively (see Fig. 1a,b).

The 660-bp DraI repeat unit also was obtained from the HindIII repeat dimer by partial restriction with DraI. The 660-bp fragment was ligated into the SmaI site of pUC18. The recombinant DNA was transformed into the $E$. coli rec $\mathrm{B}^{-}$strain $\mathrm{AB}$ 2470 (Emmerson 1968; Howard-Flanders 1968). All other cloning was performed in the E. coli rec $\mathrm{A}^{-}$strain $\mathrm{DH} 5 \alpha$ (Hanahan 1985). To generate the HindIII-truncated units $\mathrm{H}^{\prime}$ and $\mathrm{H}^{\prime \prime}$, the 660-bp HindIII repeat unit was inserted in pUCl8 and pUC13, respectively; these two constructs carry chimeric pseudogenes identical to $\psi^{\prime}$ and $\psi^{\prime \prime}$, respectively (see Fig. 1a,b).

The major oocyte 5S RNA gene clone and the somatic $5 \mathrm{~S}$ RNA gene clone are described in Xing and Worcel (1989). The $X$. laevis tRNA ${ }^{\text {met }}$ gene ( $\mathrm{pXI}^{\text {met }}{ }_{1}$, Engelke et al. 1980) was subcloned in pUC19.

The identities of the clones were confirmed by DNA sequencing. The plasmids used for transcription in vitro and in microinjection were purified by $\mathrm{CsCl}$ gradient centrifugation and phenol-chloroform extraction.

\section{Site-directed mutagenesis}

The inserts of major oocyte 5S DNA and somatic 5S DNA were released from vector pUC with EcoRI and $B a m H I$, and transferred into vector M13mp19. The single-stranded DNAs were used as templates for site-directed mutagenesis by standard procedures (Bio-Rad Kit). After the site-specific mutations were confirmed by DNA sequencing, M13 replicative-form DNA was prepared, and the double-stranded DNA was cleaved with EcoRI and BamHI to release the 5S DNA inserts, which then were transferred back to pUC18 to obtain the mutated 5S RNA gene clones.

Preparation and chromatographic fractionation of the oocyte S-150

All operations were performed at $0-4^{\circ} \mathrm{C}$, and all solutions were sterilized by autoclave and filtration. The oocyte S-150 extract was prepared as described (Glikin et al. 1984). For transcription assays, the S-150 was stored at $-70^{\circ} \mathrm{C}$ in $300-\mu 1$ aliquots; for further fractionation, the S- 150 was stored at $-70^{\circ} \mathrm{C}$ in $6-$ to 8-ml volumes before use.

Chromatographic fractionation of the S-150 extract was performed according to the procedures described by Segall et al. (1980) and Barkur et al. (1982), with some modifications. The oocyte S-150 extracts were dialyzed before chromatography against buffer A $20 \mathrm{~mm}$ HEPES $\{\mathrm{pH} 7.5\}, 0.1 \mathrm{~mm}$ EDTA, $0.5 \mathrm{~mm}$ spermine, $0.5 \mathrm{mM}$ dithiotreitol (DTT), $20 \%$ glycerol] containing $0.1 \mathrm{M} \mathrm{KCl}$ for $4 \mathrm{hr}$ at $4^{\circ} \mathrm{C}$. After a brief centrifugation to remove insoluble material, $2-3 \mathrm{ml}$ of extract $(7-10 \mathrm{mg}$ protein $/ \mathrm{ml})$ was applied to a phosphocellulose ion-exchange column (Whatman P-1 1, 2 ml lequilibrated previously with buffer A containing 0.1 $\mathrm{M} \mathrm{KCl}$. The column was washed with the same buffer, and the bound protein was step-eluted with buffer A containing $0.35 \mathrm{M}$ $\mathrm{KCl}$ to obtain fraction $\mathrm{B}$, which contained the 5S RNA transcription fraction $B$ and the $3^{\prime}$ RNA exonuclease, and then washed with buffer A containing $1.0 \mathrm{M} \mathrm{KCl}$ to obtain fraction $C$, which contained the 5S RNA transcription fraction $C$ and RNA polymerase III. The eluted fractions were pooled and dialyzed against buffer A with $0.1 \mathrm{M} \mathrm{KCl}$ for $4 \mathrm{hr}$, and then stored in $50-\mu \mathrm{l}$ aliquots at $-70^{\circ} \mathrm{C}$. The final protein concentration was $2-3 \mathrm{mg} / \mathrm{ml}$ for fraction $\mathrm{B}$ and $0.5-1 \mathrm{mg} / \mathrm{ml}$ for fraction C.

TFIIIA was purified and assayed as described previously (Xing and Worcel 1989|.

\section{Transcription reactions in vitro}

One hundred nanograms of 5S RNA gene plasmid was mixed with $35 \mu$ l of transcription buffer $[20 \mathrm{mM}$ Tris- $\mathrm{HCl}(\mathrm{pH} 7.5), 65$ $\mathrm{mM} \mathrm{KCl}, 10 \mathrm{mM} \mathrm{MgCl}, 1 \mathrm{mM} \mathrm{DTT}, 8 \%$ glycerol] and $25 \mu \mathrm{l}$ of oocyte S-150. The ribonucleoside triphosphates were added so that their concentrations in the $70-\mu l$ reaction were $0.5 \mathrm{~mm}$ each for ATP, UTP, and CTP and $20 \mu \mathrm{M}$ for GTP. Ten microcuries of $\left[\alpha^{-32} \mathrm{P}\right] \mathrm{GTP}(400 \mathrm{Ci} / \mathrm{mmol})$ was added at the beginning of the transcription reaction. For RNA microinjection experiments, high-specific-activity $\left[\alpha-{ }^{32} \mathrm{P}\right] \mathrm{GTP}(3000 \mathrm{Ci} / \mathrm{mmole})$ was used in the in vitro transcription reaction.

For 5S RNA gene transcription in the reconstituted system, $50 \mathrm{ng}$ of $5 \mathrm{~S}$ RNA gene plasmid plus $250 \mathrm{ng}$ of pUC plasmid were mixed with $20 \mu \mathrm{l}$ of transcription buffer, $40 \mathrm{ng}$ of purified TFIIIA, and $5 \mu \mathrm{l}$ each of P-11 fraction B and fraction C. RNasin ( 40 units) was added before the addition of the transcription factors. Ribonucleoside triphosphates and $\left[\alpha-{ }^{32} \mathrm{P}\right] \mathrm{GTP}$ were added as described above.

After the incubation at $25^{\circ} \mathrm{C}$, the reactions were terminated by the addition of $240 \mu \mathrm{l}$ of a stop solution containing $20 \mathrm{mM}$ EDTA, $0.5 \%$ sodium dodecyl sulfate, and $20 \mu \mathrm{g}$ of proteinase $\mathrm{K}$, and the mixture was incubated at $37^{\circ} \mathrm{C}$ for $30 \mathrm{~min}$. The RNA products were purified by phenol-chloroform extraction and by ethanol precipitation with $2 \mathrm{M}$ ammonium acetate at $-70^{\circ} \mathrm{C}$. The labeled RNAs were subjected to electrophoresis in 7.6-8.0 $\mathrm{M}$ urea- $6 \%$ polyacrylamide gels at $55^{\circ} \mathrm{C}$ (full denaturing conditions) and $4 \mathrm{M}$ urea- $15 \%$ polyacrylamide gels at $20^{\circ} \mathrm{C}$ (partial denaturing conditions) in TBE buffer $[90 \mathrm{mM}$ Tris-borate $(\mathrm{pH}$ 8.3 ), $2.5 \mathrm{mM}$ EDTA]. The gels were dried under vacuum at $80^{\circ} \mathrm{C}$ and autoradiographed against an intensifying screen at $-70^{\circ} \mathrm{C}$.

After autoradiography, the 5S RNA transcripts on the gel were located and excised. The radioactivity on the sliced gel stripes was determined by liquid-scintillation counting.

Transcription reactions in vivo (by DNA microinjection into oocytes)

Stage VI oocytes (Dumont 1972) were used, and all injections were performed into the germinal vesicles according to the 
methods described by Ryoji and Worcel (1984). The amounts of 5S RNA gene plasmid injected per oocyte was $0.5 \mathrm{ng}$ for the major oocyte and the pseudogene $5 \mathrm{~S}$ DNAs, and $0.05 \mathrm{ng}$ for the somatic 5S DNA. These 5S DNA plasmids were coinjected in $20 \mathrm{nl}$ of OR-2 media with tRNA ${ }^{\text {met }}$ gene plasmid $(0.05 \mathrm{ng})$, pUC DNA to a total DNA concentration of $2.5 \mathrm{ng}$ (Gargiulo et al. $1984)$, and $0.05 \mu \mathrm{Ci}$ of $\left[\alpha^{-32} \mathrm{P}\right] \mathrm{GTP}(400 \mathrm{Ci} / \mathrm{mmole})$. Fifteen oocytes were injected and then incubated for either $3 \mathrm{hr}$ or $18 \mathrm{hr}$ in sterile OR-2 medium at $20^{\circ} \mathrm{C}$. The oocytes were pooled and homogenized in a stop solution containing $30 \mu \mathrm{g}$ of proteinase $\mathrm{K}$, in a volume of $30 \mu \mathrm{l}$ per oocyte, and the mixture was incubated at $37^{\circ} \mathrm{C}$ for $2 \mathrm{hr}$. The RNA products were extracted twice with phenol-chloroform and once with chloroform, and they were resolved in polyacrylamide gels as described above.

\section{S RNA processing in vitro}

Three microliters of the labeled 5S RNAs, which were synthesized in the S-150 using the appropriate 5S RNA gene clones, were mixed with $10 \mu l$ of transcription buffer and 40 units of RNasin, with or without $3 \mu \mathrm{l}$ of the P-11 fraction B or fraction $\mathrm{C}$ as indicated in the figures. Incubation was for $1-2 \mathrm{hr}$ at $25^{\circ} \mathrm{C}$. The reactions were terminated by the addition of $100 \mu l$ of stop solution containing $10 \mu \mathrm{g}$ of proteinase $\mathrm{K}$, and this was followed by incubation at $37^{\circ} \mathrm{C}$ for $30 \mathrm{~min}$. To test for the presence of snRNPs, fraction $\mathrm{B}(3 \mu \mathrm{l})$ was incubated at $25^{\circ} \mathrm{C}$ for $15 \mathrm{~min}$ in $10 \mu \mathrm{l}$ of transcription buffer containing $\mathrm{CaCl}_{2}(1 \mathrm{~mm})$ and micrococcal nuclease (1-6 units). Such treatment degraded the endogenous RNA moieties present in fraction B (data not shown). The reaction was stopped with EGTA ( $2 \mathrm{mM})$. RNasin and the labeled 5S RNAs then were added to begin the RNA processing reaction in vitro.

\section{S RNA processing in vivo (by RNA microinjection into oocytes)}

The high-specific-activity 5S RNAs, which were synthesized in the S-150 using the appropriate 5S RNA gene clones and the high-specific-activity $\left[\alpha^{-32} \mathrm{P}\right] \mathrm{GTP}$, were mixed in pairs as described in the text, and they were microinjected in $20 \mathrm{nl}$ of OR-2 into either the germinal vesicle or the cytoplasm of stage VI oocytes. Fifteen oocytes were injected and then incubated in sterile OR-2 medium for $2 \mathrm{hr}$ at $20^{\circ} \mathrm{C}$. After incubation, the RNAs were extracted and resolved in polyacrylamide gels as described.

\section{Acknowledgments}

This research was supported by Public Health Service grants to A.W. We thank F. Stahl and G. Smith for $\mathrm{rec}^{-}$E. coli strains, and $M$. Sapp and D. Tremethick for their help with preparations of transcription fractions IIIB and IIIC.

\section{References}

Barkur, S., S.Y. Ng, and R.G. Roeder. 1982. Multiple factors involved in transcription of Class III genes in Xenopus laevis. J. Biol. Chem. 257: 12979-12986.

Bass, B.L. and H. Weintraub. 1988. An unwinding activity that covalently modifies its double-stranded RNA substrate. Cell 55: 1089-1098.

Bogenhagen, D.F. and D.D. Brown. 1981. Nucleotide sequences in Xenopus 5S DNA required for transcription termination. Cell 24: 261-270.

Brawerman, G. 1987. Determinants of messenger RNA stability. Cell 48: 5-6.
Brown, D.D., D. Carroll, and R.D. Brown. 1977. The isolation and characterization of a second oocyte 5S DNA from Xenopus laevis. Cell 12: 1045-1056.

Carey, M.F., S.P. Gerrard, and N.R. Cozzrelli. 1986. Analysis of RNA polymerase III transcription complexes by gel filtration. J. Biol. Chem. 261: 4309-4317.

Cotten, M., O. Gick, A. Vasserot, G. Schattner, and M.L. Birnstiel. 1988. Specific contacts between mammalian U7 snRNA and histone precursor RNA are indispensable for the in vitro 3' RNA processing reaction. EMBO J. 7: 801-808.

Denis, H. and M. Wegnez. 1973. Recherches biochimiques sur l'oogenese. Biochimie 55: 1137-1151.

Deutscher, M.P. 1985. E. coli RNases: Making sense of alphabet soup. Cell 40: 731-732.

Dumont, J.N. 1972. Oogenesis in Xenopus laevis (Daudin). I. Morphol. 136: 153-180.

Emmerson, P.T. 1968. Recombination deficient mutants of Escherichia coli $\mathrm{K} 12$ that map between thyA and argA. Genetics 60: 19-30.

Engelke, D.R., S.-Y. Ng, B.S. Shastry, and R.G. Roeder. 1980. Specific interaction of a purified transcription factor with an internal control region of 5S RNA genes. Cell 19: 717-728.

Fedoroff, N.V. and D.D. Brown. 1978. The nucleotide sequence of oocyte 5S DNA in Xenopus laevis. I. The AT-rich spacer. Cell 13: $701-716$.

Ford, P.J. and E.M. Southern. 1973. Different sequences for 5S RNA in kidney cells and ovaries of Xenopus laevis. Nat. New Biol. 241: 7-12.

Gargiulo, G., F. Razvi, and A. Worcel. 1984. Assembly of transcriptionally active chromatin in Xenopus oocytes requires specific DNA binding factors. Cell 38: $511-521$.

Georgiev, O., J. Mous, and M.L. Birnstiel. 1984. Processing and nucleo-cytoplasmic transport of histone gene transcripts. Nucleic Acids Res. 12: 8539-8551.

Glikin, G., I. Ruberti, and A. Worcel. 1984. Chromatin assembly in Xenopus oocytes: In vitro studies. Cell 37: 3341.

Hamada, H., M. Muramatsu, Y. Urano, T. Onishi, and R. Kominami. 1979. In vitro synthesis of a 5S RNA precursor by isolated nuclei of rat liver and HeLa cells. Cell 17: 163-173.

Hanahan, D. 1985. DNA cloning: A practical approach, led. D.M. Glover), vol. 1, pp. 109-114. IRL Press, Oxford.

Howard-Flanders, P. 1968. Genes that control DNA repair and genetic recombination in Escherichia coli. Adv. Biol. Med. Phys. 12: 299-317.

Jacq, B., R. Jourdan, and B.R. Jordan. 1977a. Structure and processing of precursor 5S RNA in Drosophila melanogaster. I. Mol. Biol. 117: 785-795.

Jacq, C., J.R. Miller, and G.G. Brownlee. 1977b. A pseudogene structure in 5S DNA of Xenopus laevis. Cell 12: 109-120.

Korn, L.J. 1982. Transcription of Xenopus 5S ribosomal RNA genes. Nature 295: 101-105.

Krainer, A.R. and T. Maniatis. 1985. Multiple factors including the small nuclear ribonucleoproteins $U 1$ and $U 2$ are necessary for pre-mRNA splicing in vitro. Cell 42: 725-736.

Lassar, A.B., P.L. Martin, and R.G. Roeder. 1983. Transcription of class III genes: Formation of preinitiation complexes. Science 222: 740-748.

Maniatis, T. and R. Reed. 1987. The role of small nuclear ribonucleoprotein particles in pre-mRNA splicing. Nature 325: 673-678.

Miller, J.R., E.M. Cartwright, G.G. Brownlee, N.V. Fedoroff, and D.D. Brown. 1978. The nucleotide sequence of oocyte 5S DNA in Xenopus laevis. II. The GC-rich region. Cell 13: 717-725.

Miller, J.R. and A.D. Melton. 1981. A transcriptionally active 


\section{Xing and Worcel}

pseudogene in Xenopus laevis oocyte 5S DNA. Cell 24: $829-835$.

Millstein, L., P. Eversole-Cire, J. Blanco, and J.M. Gottesfeld. 1987. Differential transcription of Xenopus oocyte and somatic-type $5 \mathrm{~S}$ genes in a Xenopus oocyte extract. $/$. Biol. Chem. 262: 1-11.

Peck, L.J., L. Millstein, P. Eversole-Cire, J.M. Gottesfeld, and A. Varshavsky. 1987. Transcriptionally inactive oocyte-type $5 S$ RNA genes of Xenopus laevis are complexed with TFIIIA in vitro. Mol. Cell. Biol. 7: 3503-3510.

Peterson, R.C., J.L. Doering, and D.D. Brown. 1980. Characterization of two Xenopus somatic 5S DNA and one minor oocyte-specific DNA. Cell 20: 131-141.

Romaniuk, P.I., I.L. de Stevenson, C. Ehresmann, P. Romby, and B. Ehresmann. 1988. A comparison of the solution structures and conformational properties of the somatic and oocyte 5S rRNAs of Xenopus laevis. Nucleic Acids Res. 16: $2295-2312$.

Ryoji, M. and A. Worcel. 1984. Chromatin assembly in Xenopus oocytes: In vivo studies. Cell 37: 21-32.

Segall, J., T. Matsui, and R.G. Roeder. 1980. Multiple factors are required for the accurate transcription of purified genes by RNA polymerase III. J. Biol. Chem. 255: 11986-11991.

Setzer, D.R. and D.D. Brown. 1985. Formation and stability of the 5S RNA transcription complex. I. Biol. Chem. 260: 2483-2492.

Sharp, P.A. 1987. Splicing of messenger RNA precursors. Science 235: 766-771.

Wakefield, L. and J.B. Gurdon. 1983. Cytoplasmic regulation of 5S RNA genes in nuclear-transplant embryos. EMBO $J$. 2: 1613-1619.

Wegnez, M., R. Monier, and H. Denis. 1972. Sequence heterogeneity of 5S RNA in Xenopus laevis. FEBS Lett. 25: 13-20.

Wolffe, A.P. 1988. Transcription factor TFIIIC can regulate differential Xenopus 5S RNA gene transcription in vitro. $E M B O$ /. 4: $1071-1079$.

Wolffe, A.P. and D.D. Brown. 1988. Developmental regulation of two 5S ribosomal RNA genes. Science 241: 1626-1632.

Wolters, J. and V.A. Erdmann. 1988. Compilation of 5S rRNA and $5 S$ rRNA gene sequences. Nucleic Acids Res. 16: rlr70.

Xing, Y.Y. and A. Worcel. 1989. The C-terminal domain of transcription factor IIIA interacts differently with different 5S RNA genes. Mol. Cell. Biol. 9: 499-514. 


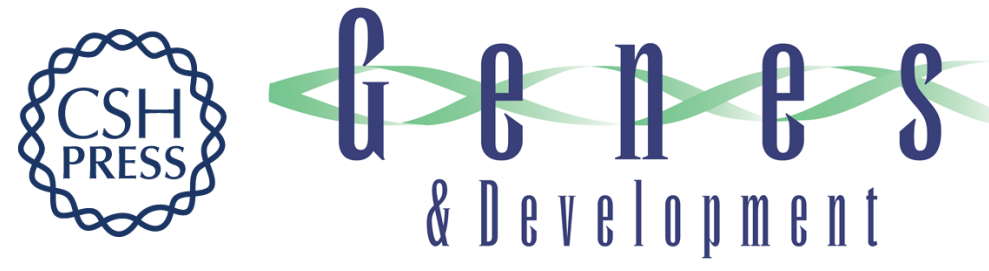

\section{A 3' exonuclease activity degrades the pseudogene 5S RNA transcript and processes the major oocyte 5S RNA transcript in Xenopus oocytes.}

Y Y Xing and A Worcel

Genes Dev. 1989, 3:

Access the most recent version at doi:10.1101/gad.3.7.1008

References This article cites 41 articles, 10 of which can be accessed free at: http://genesdev.cshlp.org/content/3/7/1008.full.html\#ref-list-1

License

Email Alerting Service

Receive free email alerts when new articles cite this article - sign up in the box at the top right corner of the article or click here.

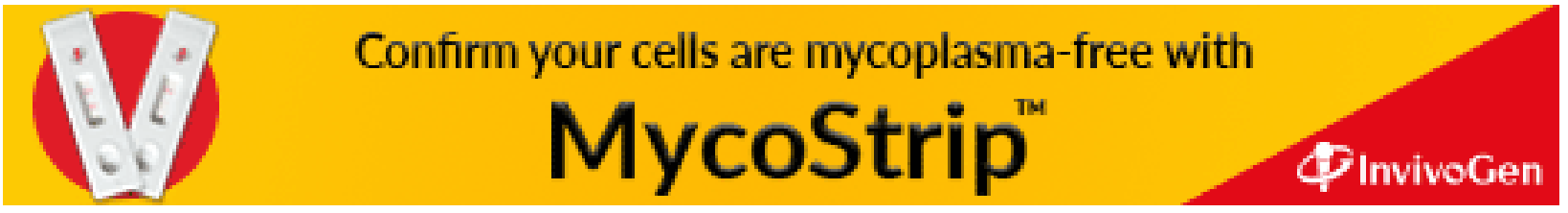

